\title{
Thyroid screening in pregnancy
}

\author{
Reena V. Wagh ${ }^{1}$, Mahavir R. Mundra ${ }^{1}$, Jayshree J. Upadhye ${ }^{2 *}$, Deepa B. Telgote ${ }^{1}$, \\ Supriya N. Khillare ${ }^{1}$, Prafulkumar S. Ramteke ${ }^{1}$
}

\author{
${ }^{1}$ Department of Biochemistry, Government Medical College, Nagpur, Maharashtra, India \\ ${ }^{2}$ Consultant Obstetrician and Gynecologist, Nagpur, Maharashtra, India
}

Received: 27 June 2017

Accepted: 25 July 2017

\section{* Correspondence:}

Dr. Jayshree J. Upadhye,

E-mail: jayshreeupadhye@gmail.com

Copyright: (C) the author(s), publisher and licensee Medip Academy. This is an open-access article distributed under the terms of the Creative Commons Attribution Non-Commercial License, which permits unrestricted non-commercial use, distribution, and reproduction in any medium, provided the original work is properly cited.

\begin{abstract}
Background: Thyroid hormone is critical to normal development of the baby's brain and nervous system. During the first trimester, the fetus depends on the mother's supply of thyroid hormone, which comes through the placenta. At around 12 weeks, the baby's thyroid begins to function on its own. In our study, complete thyroid profile of all antenatal patients was done at the first antenatal visit along with routine investigations. Aim of the study was to study the prevalence of hypothyroidism and hyperthyroidism in low income, urban pregnant women.

Methods: This is a retrospective study that includes 400 pregnant women attending the antenatal clinic at Government medical college and hospital, Nagpur in the month of April 2017. These patient's data was randomly selected in the biochemistry department where samples come. Thyroid profile is being done as a routine test along with other antenatal profile tests in our hospital. Thyroid profile test includes serum T3, serum T4 and serum TSH.

Results: A total of 400 pregnant women were included in this study. Results showed $34 \%$ prevalence of hypothyroidism of which $30 \%$ being subclinical hypothyroidism and $4 \%$ overt hypothyroidism. There was $9.5 \%$ prevalence of hyperthyroidism of which $5.5 \%$ being subclinical hyperthyroidism and $4 \%$ overt hyperthyroidism.

Conclusions: The study shows a very high prevalence rate of hypothyroidism in the patients attending the antenatal outpatient department at Government medical college and hospital, Nagpur. This justifies the inclusion of thyroid profile test as a routine test in the antenatal profile.
\end{abstract}

Keywords: Hyperthyroidism, Hypothyroidism, Pregnancy, Subclinical hypothyroidism

\section{INTRODUCTION}

Uncontrolled thyrotoxicosis and hypothyroidism are associated with adverse pregnancy outcomes. Correspondingly, there is concern about the effect of overt (i.e., symptomatic) maternal thyroid disease and even subclinical maternal thyroid disease on fetal development.

In addition, medications that affect the maternal thyroid gland can cross the placenta and affect the fetal thyroid gland. ${ }^{1}$
In 2015 there are now 7 level $A$ recommendations by ACOG

- Do not do universal screening for thyroid disease in pregnancy.

- $\quad \mathrm{TSH}$ is the first-line screening test to assess thyroid status in pregnancy.

- TSH and FT4 should be measured to diagnose thyroid disease in pregnancy.

- Treat overt hypothyroid disease in pregnancy with adequate thyroid hormone to minimize risk of adverse outcomes. 
- TSH should be monitored in pregnant women who have overt hypothyroidism and the dosage of thyroid replacement adjusted accordingly.

- Pregnant women with overt hyperthyroidism should be treated with thioamide to minimize risk and adverse outcomes.

- $\quad$ FT4 should be monitored in pregnant women with hyperthyroidism and thioamide dose adjusted accordingly. ${ }^{1}$

Only recently has a TSH of $2.5 \mathrm{mIU} / \mathrm{L}$ been accepted as the upper limit of normal for TSH in the first trimester. ${ }^{2}$ Although it is well accepted that overt hypothyroidism and overt hyperthyroidism have a deleterious impact on pregnancy, studies are now focusing on the potential impact of subclinical hypothyroidism and subclinical hyperthyroidism on maternal and fetal health, the association between miscarriage and preterm delivery in euthyroid women positive for TPO and/or Tg antibody, and the prevalence and long-term impact of postpartum thyroiditis. $^{2}$

While a strong body of research points to a clear relationship between overt thyroid disease and pregnancy complications-including miscarriage, pre-eclampsia, anemia, placental abruption, and postpartum hemorrhageevidence about the effects of subclinical thyroid disease, especially hypothyroidism, is less clear. ${ }^{3}$

2015 recommendations from the American Congress of Obstetricians and Gynecologists (ACOG) suggest testing only women at high risk of thyroid disease before they become pregnant or when they are early in pregnancy. ${ }^{3}$

Joint guidelines issued in 2005 by the American Association of Clinical Endocrinologists (AACE), ATA, and the Endocrine Society had recommended universal screening. ${ }^{3}$

Endocrine Society guidelines do not make a clear recommendation about screening in pregnancy. ${ }^{3}$

Though universal screening for thyroid dysfunction in pregnancy increases the number of women diagnosed with hypothyroidism who can be subsequently treated, it does not clearly impact maternal and fetal outcomes. ${ }^{4}$

All pregnant women should ingest approximately $250 \mu \mathrm{g}$ iodine daily. 5There is no need to initiate iodine supplementation in pregnant women who are being treated for hyperthyroidism or who are taking LT4. ${ }^{5}$

Euthyroid pregnant women who are TPOAb or TgAb positive should have measurement of serum TSH concentration performed at time of pregnancy confirmation and every 4 weeks through midpregnancy. ${ }^{5}$

Evaluation of serum TSH concentration is recommended for all women seeking care for infertility. ${ }^{5}$ LT4 treatment is recommended for infertile women with overt hypothyroidism who desire pregnancy. ${ }^{5}$

The fetal thyroid gland begins synthesizing thyroid hormone after 12 weeks of gestation. Thyroid hormone is supplied to the fetus by the mother before this time, and it is at this time that thyroid hormones are most important for fetal brain development. However significant fetal brain development continues beyond first trimester, making thyroid hormone also important in later gestation. ${ }^{6}$

Women with overt hypothyroidism are at an increased risk for pregnancy complications such as early pregnancy failure, preeclampsia, placental abruption, low birth weight and still birth. Treatment of women with overt hypothyroidism has been associated with improved pregnancy outcomes. ${ }^{6}$

Overt hypothyroidism in pregnancy, defined as an elevated serum thyroid-stimulating hormone (TSH) and reduced serum free thyroxine or a TSH $>10 \mathrm{mIU} / \mathrm{L}$, is known to have adverse effects on pregnancy. Subclinical hypothyroidism is typically defined as an elevated TSH and normal FT4 levels. ${ }^{7}$

Treatment is necessary when TSH is 10 or more, regardless of the T4 level. In addition, TSH should be monitored every 4 weeks during the first 20 weeks of gestation, then once again between 26 and 32 weeks. ${ }^{8}$

\section{METHODS}

This is an observational retrospective study. The cases of this study were recruited from the biochemistry department where samples are received from outpatient department of Obstetrics and Gynaecology in the month of April 2017. Serum TSH is the most convenient and best test to diagnose thyroid disease in pregnancy in first trimester.

\section{The new recommendations for TSH levels during pregnancy are the following}

- $\quad$ First trimester: less than 2.5 with a range of 0.1-2.5

- Second trimester: 0.2-3.0

- Third trimester: 0.3-3.0.

\section{Exclusion criteria}

- $\quad$ Pregnant women with pre-existing medical disorders like diabetes, heart disease, collagen disease etc.

- Women taking drugs known to alter thyroid level (e.g. amphetamines, dopamine agonist, amiodarone, steroids)

\section{RESULTS}

In present study, 53\% patients were in the age group 2630 years, $26 \%$ patients were in the age group $21-25$ years, 
$20 \%$ patients were in the age group 31-35 years while $1 \%$ patients were in the age group 36-40 years.

Table 1: Age group.

\begin{tabular}{|c|c|c|}
\hline Age group & No. of patients & $\%$ \\
\hline $21-25$ years & 104 & 26 \\
\hline $26-30$ years & 212 & 53 \\
\hline $31-35$ years & 80 & 20 \\
\hline $36-40$ years & 4 & 1 \\
\hline
\end{tabular}

Table 2: Parity.

\begin{tabular}{|lll|}
\hline Parity & No. of patients & $\%$ \\
\hline Primi & 284 & 71 \\
\hline Multi & 116 & 29 \\
\hline
\end{tabular}

In present study, $71 \%$ of the patients were primigravida and $29 \%$ of the patients were multigravida.

Table 3: BMI (body mass index).

\begin{tabular}{|lll|}
\hline BMI & No. of patients & $\%$ \\
\hline$<17.9 \mathrm{~kg} / \mathrm{m}^{2}$ underweight & 6 & 1.5 \\
\hline $18-22.9 \mathrm{~kg} / \mathrm{m}^{2}$ normal & 320 & 80 \\
\hline$>23 \mathrm{~kg} / \mathrm{m}^{2}$ overweigh & 68 & 17 \\
\hline$>25 \mathrm{~kg} / \mathrm{m}^{2}$ obese & 6 & 1.5 \\
\hline
\end{tabular}

In our study, $80 \%$ girls had normal BMI, $17 \%$ were overweight, $1.5 \%$ were obese while $1.5 \%$ were underweight.

Overweight and obese women are more likely to have hypothyroidism. Counselling was done and weight reduction was advised.

Table 4: Overt and subclinical hypothyroidism.

\begin{tabular}{|lll|}
\hline Hypothyroidism & No. of patients & $\%$ \\
\hline Overt hypothyroidism & 16 & 4 \\
\hline Subclinical hypothyroidism & 120 & 30 \\
\hline Total & 136 & 34 \\
\hline
\end{tabular}

In our study, total prevalence of hypothyroidism was $34 \%$. Out of this, overt hypothyroidism was seen in $4 \%$ of patients whereas subclinical hypothyroidism was seen in $30 \%$ of patients. This is quite high prevalence of subclinical hypothyroidism.

Table 5: Overt and subclinical hyperthyroidism.

\begin{tabular}{|lll|}
\hline Hyperthyroidism & No. of patients & $\%$ \\
\hline Overt hyperthyroidism & 16 & 4 \\
\hline Subclinical hyperthyroidism & 22 & 5.5 \\
\hline Total & 38 & 9.5 \\
\hline
\end{tabular}

In our study, total prevalence of hyperthyroidism was $9.5 \% \%$. Out of this, overt hyperthyroidism was seen in
$4 \%$ of patients whereas subclinical hyperthyroidism was seen in $5.5 \%$ of patients.

\section{DISCUSSION}

In current study, 53\% patients were in the age group 2630 years, $26 \%$ patients were in the age group 21-25 years, $20 \%$ patients were in the age group 31-35 years while $1 \%$ patients were in the age group 36-40 years. $71 \%$ of the patients were primigravida and $29 \%$ of the patients were multigravida.

In present study, $80 \%$ girls had normal BMI, $17 \%$ were overweight, $1.5 \%$ were obese while $1.5 \%$ were underweight. Total prevalence of hypothyroidism was $34 \%$. Out of this, overt hypothyroidism was seen in $4 \%$ of patients whereas subclinical hypothyroidism was seen in $30 \%$ of patients. Green A et al found that overt hypothyroidism affects up to $1 \%$ of all pregnancies. But subclinical hypothyroidism affects between $3 \%$ and $15 \%$ of pregnancies. ${ }^{2}$

Levenson $\mathrm{D}$ et al found that thyroid disease affects approximately $5 \%$ of $\mathrm{U}$. S. women of reproductive age and has been associated with complications in pregnant women and their children. ${ }^{3}$ The debate began with a 1999 study that found children ages 7 to 9 born to women with undetected thyroid deficiency had IQ scores that averaged 7 points lower than IQ scores of children of treated control subjects. ${ }^{3}$

Patibandla R found that out of 1062 cases, 149 (14.03\%) cases demonstrated subclinical hypothyroidism, 66 cases $(6.2 \%)$ had overt hypothyroidism and 7 cases $(0.6 \%)$ had hyperthyroidism. ${ }^{6}$ They found that $70 \%$ subclinical hypothyroidism and $30 \%$ overt hypothyroidism out of total hypothyroid cases. ${ }^{6}$ The results showed $20.1 \%$ prevalence, $14.03 \%$ being subclinical hypothyroidism and $6.6 \%$ overt hypothyroidism. The upper limit of TSH is taken as $2.5 \mathrm{mIU} / \mathrm{Lin} 1^{\text {st }}$ trimester and $3 \mathrm{mIU} / \mathrm{L}$ in $2^{\text {nd }}$ and $3^{\text {rd }}$ trimester. $^{6}$

According to ACOG, the prevalence of subclinical hypothyroidism has been anticipated to be between $2 \%$ and 5\%. ${ }^{6}$ Cignini $\mathrm{P}$ et al found that hypothyroidism occurs in $2.5 \%$ of pregnancies; however, the frequency of $\mathrm{OH}$ is estimated to be between 0.2 and $1.0 \% .^{7}$ They found that prevalence of $\mathrm{SH}$ varies between 1.5 and $4.0 \% .^{9}$

In present study, total prevalence of hyperthyroidism was $9.5 \% \%$. Out of this, overt hyperthyroidism was seen in $4 \%$ of patients whereas subclinical hypothyroidism was seen in $5.5 \%$ of patients. Cignini $\mathrm{P}$ et al found that hyperthyroidism occurs in $0.1-0.4 \%$ of pregnant women. Whereas about $2-3 \%$ of pregnant women are hypothyroid, of whom $0.3-0.5 \%$ have overt hypothyroidism and $2-2.5 \%$ present subclinical hypothyroidism. ${ }^{9}$ They found hyperthyroidism as less common than hypothyroidism and is seen in only $0.2 \%$ of pregnancies. ${ }^{9}$ 
Mestman $\mathrm{N}$ found that hyperthyroidism occurs in 0.1 $0.4 \%$ of pregnant women. Whereas about $2-3 \%$ of pregnant women are hypothyroid, of whom $0.3-0.5 \%$ have overt hypothyroidism and $2-2.5 \%$ present subclinical hypothyroidism. ${ }^{10}$ Taylor $\mathrm{P}$ et al studied 13,224 pregnant women; 12,608 had normal thyroid function, 340 had subclinical hypothyroidism (SCH), 305 had isolated hypothyroxinemia (IH). 10 treatments had no discernible effect on the composite outcome. ${ }^{10}$ Both $\mathrm{SCH}$ and IH were associated with key adverse obstetric outcomes. Although there was no difference in composite outcome there were some benefits observed with levothyroxine therapy. ${ }^{11}$

A study from Maulana Azad Medical College, New Delhi, 2011 by Dhanwal DK et al concluded that subclinical hypothyroidism is common in North India. ${ }^{12}$ A study done at Government Medical College and Hospital, Chandigarh, 2012 by Goel P et al showed prevalence of hypothyroidism was $6.3 \% .{ }^{13}$ Sisodia J et al gives the prevalence of hypothyroidism in pregnancy $3.7 \% .{ }^{13}$ They found that age of hypothyroid pregnant women varied from 20-35 years, with median age of 25 years. $^{14}$

\section{CONCLUSION}

The study shows a very high prevalence rate of hypothyroidism compared with the prevalence of hyperthyroidism in the patients attending the antenatal outpatient department. This justifies the inclusion of thyroid profile test as a routine test in the antenatal profile.

\section{Funding: No funding sources}

Conflict of interest: None declared

Ethical approval: The study was approved by the Institutional Ethics Committee

\section{REFERENCES}

1. Sarah J. Kilpatrick, ACOG Practice Bulletin Number 148: Thyroid disease in pregnancy. Obstet Gynecol. 2015;125:996-1005.

2. Stagnaro-Green A, Abalovich M. Guidelines of the American thyroid association for the diagnosis and management of thyroid disease during pregnancy and postpartum. Thyroid. 2011;21(10):1081-1125.
3. Levenson D. The Debate Over Universal TSH Screening in Pregnancy Continues, Clinical Laboratory New; 2015.

4. Spencer L, Bubner $\mathrm{T}$, Bain $\mathrm{E}$, Middleton $\mathrm{P}$, Screening and subsequent treatment for thyroid dysfunction before or during pregnancy to improve outcomes for mothers and their babies, Cochrane;2015.

5. Alexander EK, Pearce EN. Guidelines of the American thyroid association for the diagnosis and management of thyroid disease during pregnancy and the postpartum. Thyroid; 2017;27(3).

6. Rao S, Patibandla A. A study to find out the Prevalence of Hypothyroidism among Pregnant Women Visiting ESI Hospital Sanathnagar Hyderabad. Gynecol Obstet (Sunnyvale). 2016;6:363.

7. Kroopnick JM, Kim CS. Overview of hypothyroidism in pregnancy. Semin Reprod Med. 2016;34(06):323-30.

8. Fryhofer S. Guidelines for Thyroid Disease in Pregnancy: Key Points, Medscape; 2017.

9. Cignini P, Cafa EV. Thyroid physiology and common diseases in pregnancy: review of literature. J Prenat Med. 2012;6(4):64-71.

10. Negro R, Mestman JH. Thyroid disease in pregnancy. Best practice and research. Clin Endocrinol Metab. 2011;25(6):927-43.

11. Taylor P, Lacey A. Controlled Antenatal Thyroid Screening Study. Obstetric Outcomes, Endocrine Abstracts. 2016;44:OC6.3.

12. Dhanwal DK, Prasad S, Agarwal AK, Dixit V, Banerjee AK. High prevalence of subclinical hypothyroidism during first trimester of pregnancy in North India. Indian J Endocr Metab. 2013;17:281-4.

13. Goel P, Kaur J, Saha PK, Tandon R, Devi L. Prevalence, associated risk factors and effects of hypothyroidism in pregnancy: A study from North India. Gynecol Obstet Invest. 2012;74(2):89-94.

14. Sisodia J, Samant M, Antenatal thyroid screening and its clinical correlation, International Journal of Reproduction, Contraception, Obstetrics and Gynecology. Int J Reprod Contracept Obstet Gynecol. 2017;6(5):1864-70.

Cite this article as: Wagh RV, Mundra MR, Upadhye JJ, Telgote DB, Khillare SN, Ramteke PS. Thyroid screening in pregnancy. Int J Reprod Contracept Obstet Gynecol 2017;6:3956-9. 